\title{
Characterisation of connective tissue cells containing factor XIII subunit $a$
}

\author{
RÓZA ÁDÁNY, ${ }^{*}$ MARINA A GLUKHOVA, $\dagger$ AY KABAKOV, $†$ L MUSZBEK* \\ From the *Department of Clinical Chemistry, University School of Medicine, Debrecen, Hungary, and the \\ †Cardiology Research Center, Moscow, USSR
}

SUMMARY Paraffin embedded sections of human liver, lymph node, and placenta showed that certain connective tissue cells were positive for factor XIII subunit $a$. These cells were further characterised by double immunofluorescence labelling and by combined immunofluorescence and enzyme cytochemical staining on frozen sections. They were labelled by the monoclonal antibodies RFD7 and anti-Leu M3 (markers of the macrophage cell line) but gave a negative reaction for the fibroblast marker IIG10 and showed no alkaline phosphatase activity.

Immunoblotting detected factor XIII subunit $a$ in macrophages isolated from placenta but not in human fibroblasts.

At lower dilutions, the commercially available antibody against the $b$ subunit of factor XIII also positively reacted with the same cell population. The facts that immunoblotting showed that the antiserum crossreacted with the $a$ subunit and that placental macrophages did not stain strongly for the $b$ subunit also indicate that this antigen is not present in adult connective tissue cells.

Factor XIII is a plasma pro-transglutaminase consisting of $a$ and $b$ subunits in a tetrameric structure $\left(\mathrm{a}_{2} \mathrm{~b}_{2}\right)$. During the process of blood coagulation activated factor XIII $\left(a_{2}\right)$ acts as a catalyst for the formation of isopeptide bonds between polymerising fibrin molecules.'

A cellular form of factor XIII consisting exclusively of $a$ subunits has also been shown in platelets ${ }^{23}$ and monocytes, ${ }^{45}$ though the function of the intracellular factor is not fully known.

Data accumulated over the past two decades clearly suggest that the role of factor XIII is not restricted to the area of haemostasis, and certain findings indicate the possible role of factor XIII in connective tissue organisation. The impaired wound healing of patients deficient in factor $\mathrm{XIII}^{67}$ and its stimulatory effect on fibroblast proliferation ${ }^{68}$ have been known for a long time. It was also shown that fibronectin 110 and collagen $^{11}$ serve as substrates for factor XIII. Fear et $a l^{\prime 2}$ showed that both subunits of factor XIII were present in cells of different connective tissues, and without immunomorphological or enzyme cytochemical characterisation, they interpreted these cells as fibroblasts. More recently we have shown that

Accepted for publication 25 June 1987 factor XIII subunit $a$ is retained during the differentiation of monocytes into macrophages. ${ }^{12-15}$

As histiocytes (tissue macrophages) belong to the mononuclear phagocyte system and are generally considered to be derived from circulating blood monocytes, ${ }^{16}$ it seemed reasonable to us that connective tissue macrophages also express factor XIII subunit $a$. This hypothesis prompted us to reinvestigate the presence of factor XIII subunits in connective tissue cells and to attempt to characterise the cells expressing either of the factor XIII subunits.

\section{Material and methods}

Tissue sections examined included three histologically normal specimens of human liver, lymph node obtained at necropsy, and full term placenta. Tissue samples were divided into two parts: one part was fixed in $3.5 \%$ paraformaldehyde fixative for six hours and then vacuum embedded in paraffin; the other part was snap frozen. Sections $(6 \mu \mathrm{m})$ were cut from both paraffin embedded and frozen blocks.

Human adult foreskin fibroblasts were cultivated according to Brown et al. ${ }^{17}$ Cells at passage number 20 were harvested for the experiments.

Human citrated venous blood was centrifuged at $400 \mathrm{~g}$ for 10 minutes at $20^{\circ} \mathrm{C}$. Platelet rich plasma was 
removed and pelleted $\left(3000 \mathrm{~g}\right.$ for 10 minutes at $\left.4^{\circ} \mathrm{C}\right)$. The pellet was resuspended and washed twice in phosphate buffered saline (PBS), pH 7.4, containing $5 \mathrm{mmol} / 1$ ethylene-diaminotetra-acetic acid. Mixed placental suspension was prepared according to the method of Butterworth and Loke ${ }^{18}$ with the exception that after a preliminary trypsin digestion for 10 minutes the suspension was filtered through three layers of gauze to remove syncytial cells. The denuded villi were further digested and the isolated cells were washed in PBS containing $5 \mathrm{mmol} / \mathrm{l}$ edetic acid. Macrophages were isolated from the mixed placental cell population by a separation technique for peripheral blood monocytes. ${ }^{19}$ Viability and the phagocytic activity of isolated cells were tested according to the method of Bevilacqua et al..$^{20}$ Ninety seven per cent of the cells did not stain with Trypan blue and $90 \%$ of them phagocytosed at least three latex particles during one hour of incubation at $37^{\circ} \mathrm{C}$. Cells were washed three times in PBS containing $5 \mathrm{mmol} / \mathrm{l}$ edetic acid. Cell smears were prepared by using a Cytospin 2 centrifuge (Shandon Southern Products Ltd, Cheshire, England) and were stained for factor XIII subunit $a$ by an indirect immunofluorescence method for frozen sections.

\section{CELL EXTRACTS}

Cultures of fibroblasts were mechanically removed and dissolved in sample buffer prepared according to Laemmli. ${ }^{21}$ The same denaturing solution was used to prepare extracts of human platelets as well as to dissolve the cells isolated from human full term placenta. Cell extracts were briefly sonicated (three $\times 30$ seconds) and boiled for five minutes. The protein content of denatured cell extracts was determined by BCA protein assay reagent (Pierce Chemical Company, Rockford, Illinois, USA) using bovine serum albumin as standard.

\section{IMMUNOPEROXIDASE STAINING ON PARAFFIN SECTIONS}

Reactions for factor XIII subunits were carried out using Vectastain rabbit ABC kit (Vector Laboratories, Burlingame, California, USA) as described earlier. ${ }^{14}$ Primary antisera against subunits $a$ and $b$ (Behringwerke, Marburg, Germany; batch Nos 105814B and $105906 \mathrm{C}$, respectively) were used at different dilutions $(1 / 10,1 / 20,1 / 40,1 / 80,1 / 160$ and $1 / 320$ in PBS containing $20 \%$ normal goat serum). Identical dilutions of normal rabbit serum were used in the case of negative control slides. Preparations were counterstained with Mayer's haematoxylin.

DOUBLE IMMUNOFLUORESCENCE LABELLING ON FROZEN SECTIONS

Cryostat sections of different organs were fixed in acetone for 10 minutes at $4^{\circ} \mathrm{C}$. Aspecific IgG binding was blocked by preincubation with $5 \%$ normal goat serum diluted in PBS for 25 minutes. Factor XIII subunit $a$ was detected by an indirect immunofluorescence reaction on samples incubated with the first antiserum (1/200 dilution in PBS) for two hours and with a 1/40 dilution of swine antirabbit IgG conjugated with fluorescein isothiocyanate (FITC) (Dakopatts a/s, Glostrup, Denmark) for 45 minutes. This reaction was combined with one of the following immunoreactions.

1 Detection of Leu M3, a surface marker of monocyte/macrophage cell line $e^{223}$ (45 minutes of incubation with $1 / 5$ dilution of a monoclonal antibody conjugated with phycoerythrein; Becton Dickinson, Sunnyvale, California, USA).

2 Visualisation of a specific antigen of tissue histiocytes by RFD7 monoclonal antibody ${ }^{24}$ (45 minutes of incubation with a $1 / 2$ dilution of culture supernatant; Royal Free Hospital, London, England). 3 Immunostaining for HLA-DR antigen (45 minutes of incubation with a $1 / 5$ dilution of a biotinylated monoclonal antibody against HLA-DR; Becton Dickinson).

4 Detection of a polypeptide antigen of molecular weight $330 \mathrm{kD}$ localised on the surface of fibroblasts and smooth muscle cells by IIG10 monoclonal antibody $^{25}$ (incubation with a $1 / 20$ dilution of hybridoma supernatant for one hour).

For steps 2 and 4, horse biotinylated antimouse IgG (Vector Laboratories) was used as second antibody (1/ 250 dilution for 30 minutes). Biotinylated antibodies were visualised by incubation with a 1/40 dilution of Texas Red streptavidin (Amersham International, Little Chalfont, England) for $\mathbf{4 5}$ minutes.

On control slides non-immune rabbit serum was replaced for antiserum against factor XIII subunit $a$, while control mouse IgG from tumor bearing BALB/c mice (Becton Dickinson) was substituted for monoclonal antibodies. Washing was carried out with PBS. Sections were covered with $50 \%$ glycerol in PBS and examined by Opton ultraviolet microscope equipped with an epifluorescence condensor containing selective filters for FITC and Texas Red/phycoerythrein. Fluorescence photomicrographs were taken using Ilford HP5 or Revue superchrome films.

As a first step, factor XIII subunit $a$ was detected by indirect immunofluorescence, as described above. After washing in distilled water the activity of alkaline phosphatase present in fibroblasts, but not in monocytes or macrophages ${ }^{26}$ was developed by 15 minutes of incubation at $37^{\circ} \mathrm{C}$ in naphtol AS-MX phosphate buffer ${ }^{27}$ containing $1 \mathrm{~g} / 1$ fast red TR salt. The specificity of the enzyme cytochemical reaction for alkaline phosphatase was checked by the omission of substrate from the incubation medium. Slides were 
mounted in $50 \%$ glycerol in PBS and examined by ultraviolet microscope on an FITC channel. Fields photographed at fluorescence excitation were rephotographed in normal light.

Sodium dodecyl sulphate-polyacrylamide gel electrophoresis $(10 \%)$ (SDS PAGE) ${ }^{21}$ and immunoblotting of denatured placental cell extract for factor XIII subunits were carried out as described previously. ${ }^{4}$ The same procedure was used for fibroblasts and platelets, with the modifications that a $5-15 \%$ gradient gel was used in SDS PAGE and that $0 \cdot 5 \%$ 4-chloro-1-naphtol was used as chromogen.

\section{Results}

Immunoperoxidase staining of factor XIII subunit $a$ in sections of human liver and placenta gave patterns similar to those obtained earlier by Fear et al. ${ }^{12}$ Briefly, liver cells labelled for factor XIII subunit $a$ were localised in the connective tissue of the portal tract; Kupffer cells and hepatocytes were negative. In the placenta only certain mesenchymal cells were labelled for this antigen. In the lymph node some of the positive cells were found in the capsular connective tissue.
Other cells positive for factor XIII in the lymphoreticular tissue have already been characterised and the results published in a separate paper. ${ }^{28}$ Cells labelled for factor XIII subunit $a$ appeared mainly as spindle-shaped, fibroblast-like elements in adult connective tissue, while a stellate morphological appearance was observed in mesenchymal cells.

\section{IMMUNOMORPHOLOGICAL AND ENZYME}

CYTOCHEMICAL CHARACTERISATION OF CELLS

POSITIVE FOR FACTOR XIII SUBUNIT $A$

On frozen sections of full term placenta, mesenchymal cells containing factor XIII subunit $a$ were almost equally positive for both RFD7 (fig 1) and Leu M3 (fig 2). After simultaneous detection of factor XIII subunit $a$ and IIG10, a surface marker of fibroblasts, no double labelled cells were observed in the mesenchyme (fig 3).

Similar results were obtained on frozen sections of liver and lymph node by using the same double labelling systems - that is, cells positive for factor XIII subunit $a$ also stained for Leu M3 and RFD7 (data not shown), but not for IIG10. When the detection of alkaline phosphatase activity was combined with the
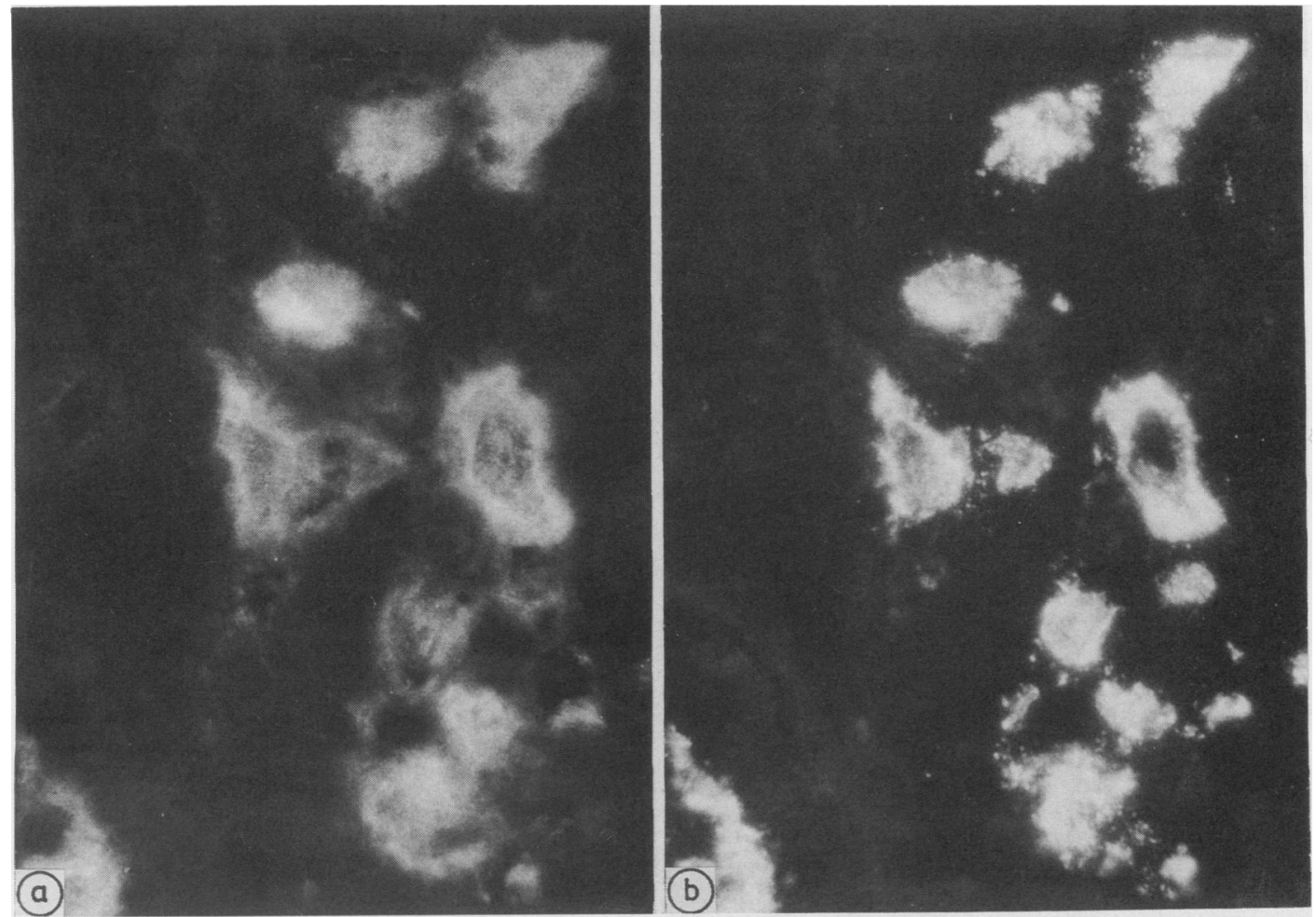

Fig 1 Simultaneous expression of FXIII subunit $a(a)$ and RFD7 (b) on identical chorionic mesenchymal cells of full term placenta. (Double immunofluorescence labelling). 

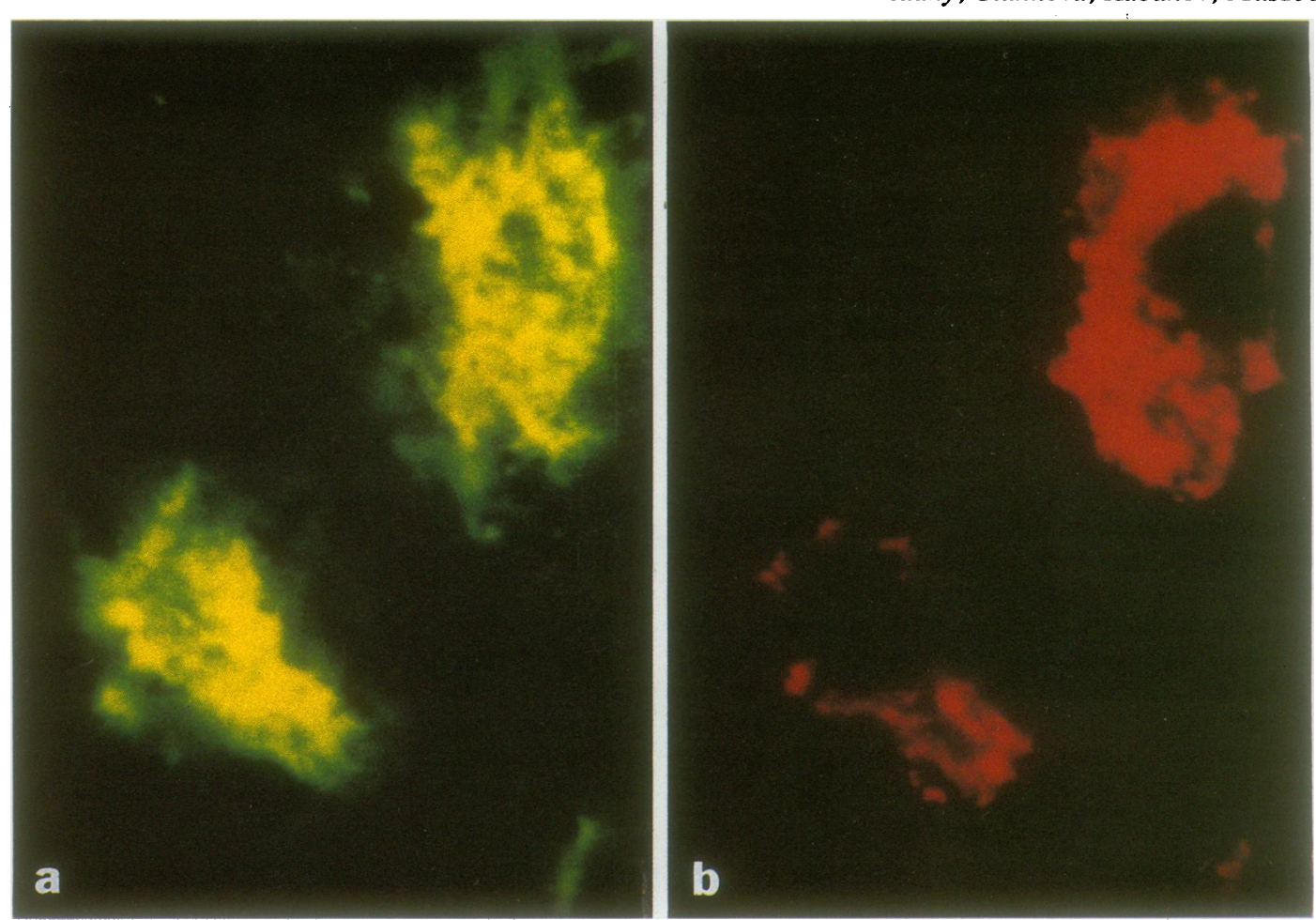

Fig 2 Double immunofluorescence labelling for FXIII subunit a (a) and Leu M3 (b) on frozen section of full term placenta. Identical cells of chorionic mesenchyme were labelled for both antigens.

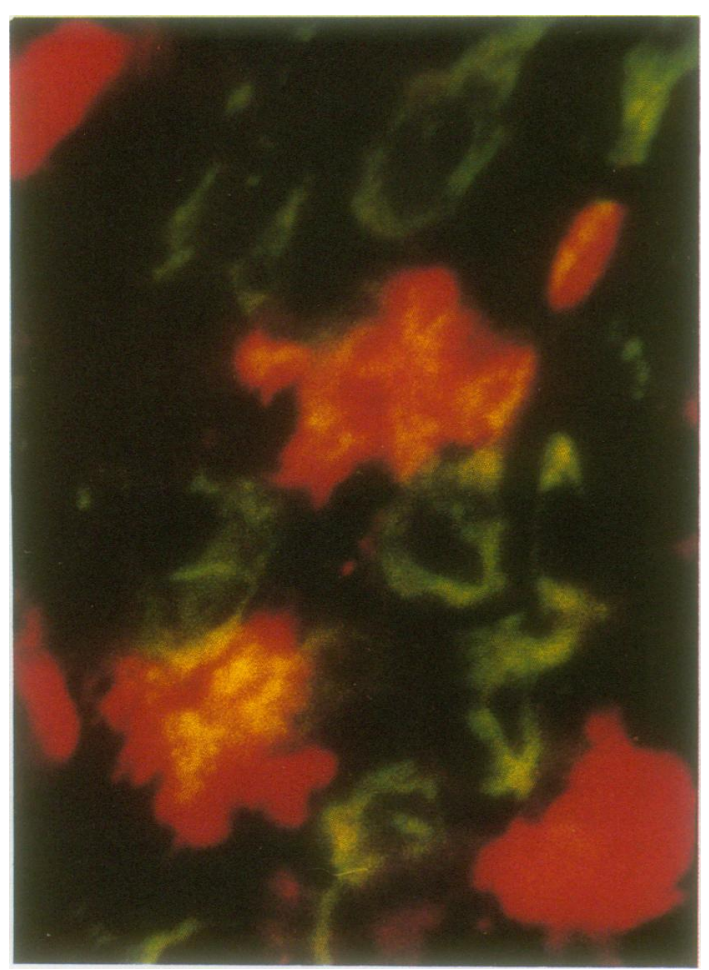

Fig 3 Double immunofluorescence labelling for FXIII subunit a (red colour) and IIGIO (green colour) on frozen section of full term placenta. Non-overlapping cell populations were visualised. 
immunofluorescence reaction for factor XIII subunit $a$, the two reactions labelled different cell populations (fig 4). The only difference in the marker reactions of cells containing factor XIII subunit $a$ in the mesenchymal tissue of placenta and in adult connective tissue of lymph node and liver was the different expression of HLA-DR antigen. Cells positive for factor XIII of adult connective tissue were strongly positive for HLA-DR (fig 5), while those cells of mesenchyme were negative or only weakly positive (data not shown). The results obtained by double immunofluorescence are summarised in the table.

\section{DETECTION OF FACTOR XIII SUBUNIT $A$ BY IMMUNOBLOTTING}

The absence of factor XIII subunit $a$ in human fibroblasts and its presence in placental macrophages was clearly shown by immunoblotting (figs 6 and 7). About $70 \%$ of mesenchymal macrophages isolated from human placenta stained for factor XIII subunits $a$ and $b$. After immunoblotting with a nitrocellulose sheet of placental cell proteins and resolution on $10 \%$ SDS-PAGE, a single protein band comigrating with subunit $a$ of factor XIII could be detected by antiserum against subunit $a$ (fig 7). In a separate experiment no protein band of fibroblast extract was stained by the same antibody (fig 6).

\section{SUBUNIT $B$ OF FACTOR XIII IN CONNECTIVE \\ TISSUE CELLS}

The cell population labelled for factor XIII subunit $a$ by immunoperoxidase and immunofluorescence techniques was also stained by the commercially available antiserum against the $b$ subunit, though a stronger antiserum was required to obtain a positive reaction. The antiserum against the $b$ subunit cross reacted with the $a$ subunit of purified factor XIII and of factor XIII present in placental macrophages (fig 7).

\section{Discussion}

Recently Fear et al reported that certain cells in the connective tissue contained both $a$ and $b$ subunits of factor XIII, and they presumed that these cells were inactive fibroblasts. ${ }^{12}$ In a subsequent paper from the same laboratory, both factor XIII subunits were

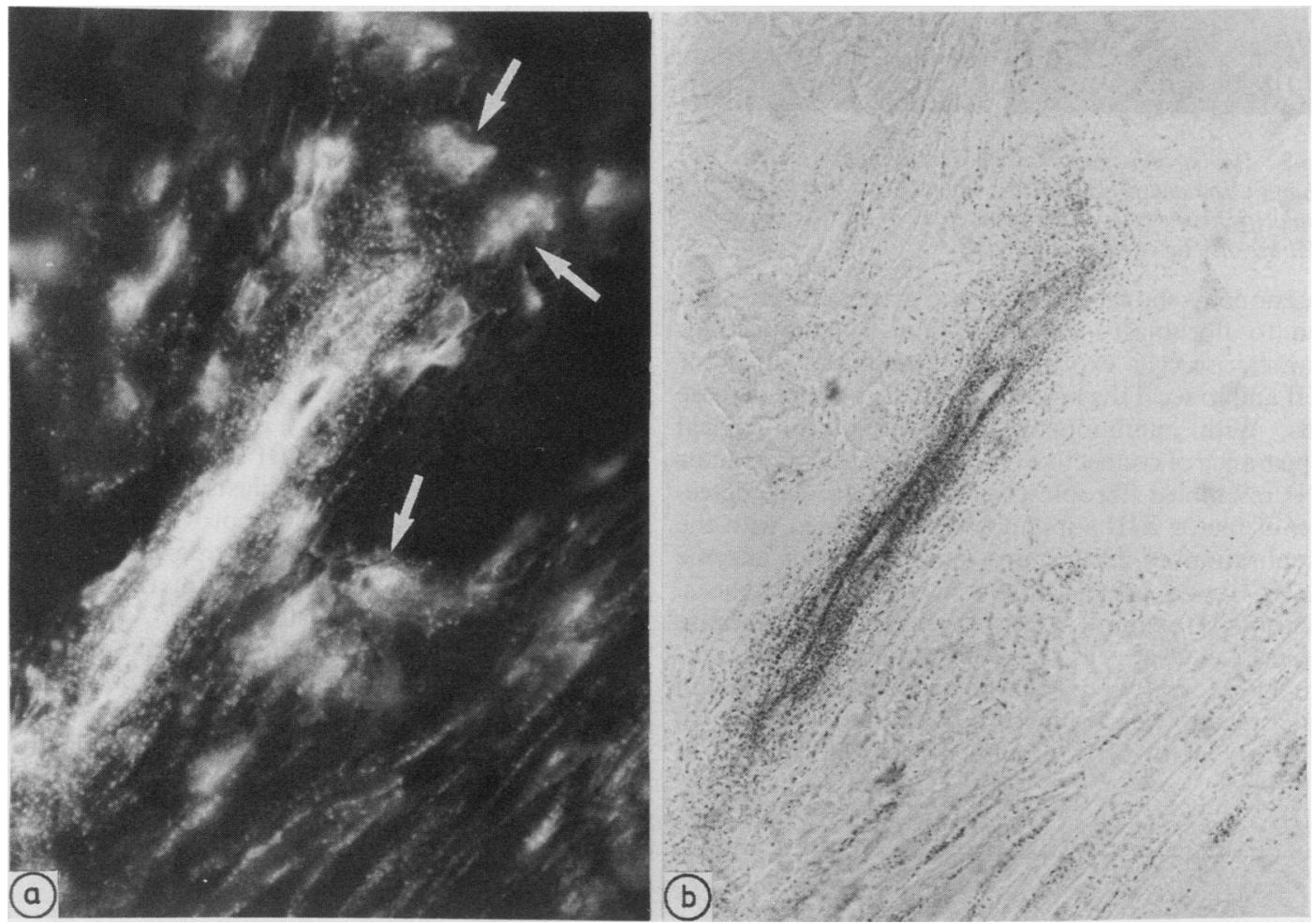

Fig 4 Detection of factor XIII subunit a (a) combined with enzyme cytochemical reaction for alkaline phosphatase activity $(b)$ in capsular connective tissue of human lymph node. Endothelial cells and fibroblasts showing positive reaction for alkaline phosphatase can also be seen on FITC channel of ultraviolet microscope. Cells positive for factor XIII subunit a do not contain alkaline phosphatase. 


\section{a}

Fig 5 Double immunofluorescence labelling for factor XIII subunit $a(a)$ and $H L A-D R(b)$ on frozen section of liver in connective tissue cells of portal tract. Cells positive for factor $X I I I$ are also labelled for $H L A-D R$.

occasionally shown in histiocytic giant cells, in addition to fibroblast-like cells. ${ }^{29}$ Our study aimed to characterise cells expressing the $a$ subunit of factor XIII and to see if the $b$ subunit is really present in these cells. With immunoperoxidase, the morphological appearance of connective tissue cells containing factor XIII resembled fibroblasts or histiocytes. The detection of factor XIII subunit $a$ was combined with the visualisation of marker antigens or marker enzyme known to be present in histiocytes or fibroblasts. Factor XIII subunit $a$ was expressed only in those connective tissue cells positive for macrophage markers RFD7 and Leu M3. Its presence in placental macrophages was also shown by immunoblotting. In contrast, factor XIII subunit $a$ was not detected in
Ádány, Glukhova, Kabakov, Muszbek

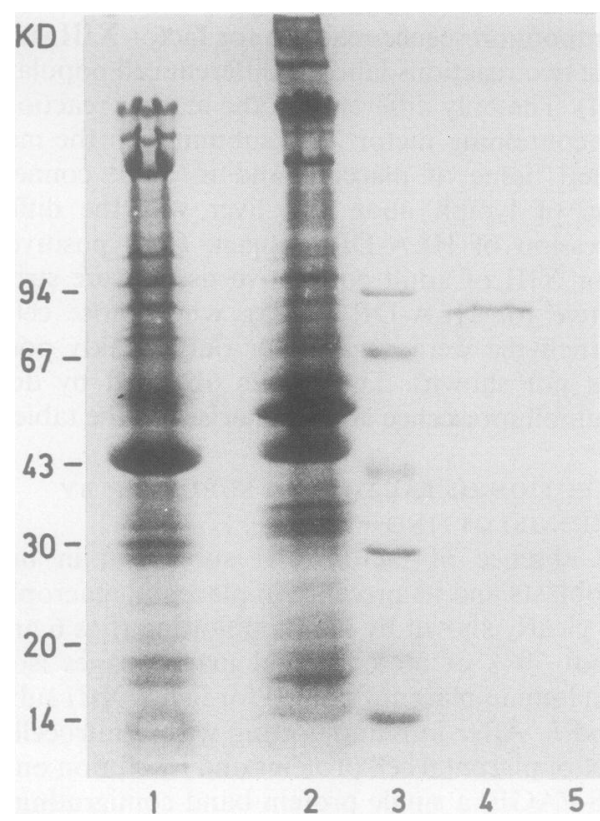

Fig 6 SDS-PAGE pattern of platelet (track 1; $160 \mu \mathrm{g}$ ), cultured foreskin fibroblast (track 2; $160 \mu \mathrm{g}$ ) homogenate and $M$, standards (track 3) stained by Coomassie blue. Proteins from identical gel segment were electrophoretically transferred to nitrocellulose paper, which was then developed for factor XIII subunit a (tracks 4, 5). Factor XIII subunit a was present only in platelet extract (track 4).

cultured fibroblast cells. Though the expression of certain antigens might be lost at culture, all cells stained for the fibroblast markers IIIG10 and alkaline phosphatase lack this antigen. This clearly suggests that factor XIII subunit $a$ is not present in human fibroblasts.

The finding that factor XIII subunit $a$ is expressed by histiocytes but not by fibroblasts might be of certain relevance. Its application might provide valuable new data to the controversy on the origin of malignant fibrous histiocytoma ${ }^{30} 31$ unless this marker reaction is lost during malignant transformation.

Fetal (placental) and adult connective tissue cells containing factor XIII subunit $a$ differed only in the expression of HLA-DR. The lack of HLA-DR in placental macrophages, also observed by Bulmer and

Table Marker reactions of connective tissue cells containing factor XIII subunit a

\begin{tabular}{|c|c|c|c|c|c|}
\hline \multirow[b]{2}{*}{ Tissue sections } & \multicolumn{5}{|c|}{ Characteristics } \\
\hline & Leu $M 3$ & $R F D 7$ & $H L A-D R$ & $I I G 10$ & $\boldsymbol{A P}$ \\
\hline $\begin{array}{l}\text { Capsular connective tissue of lymph node } \\
\text { Portal connective tissue of liver } \\
\text { Chorionic mesenchyme }\end{array}$ & $\begin{array}{l}+ \\
+ \\
+\end{array}$ & $\begin{array}{l}+ \\
+ \\
+\end{array}$ & $\begin{array}{l}+ \\
+ \\
-\end{array}$ & $\begin{array}{l}- \\
-\end{array}$ & $\begin{array}{l}- \\
-\end{array}$ \\
\hline
\end{tabular}




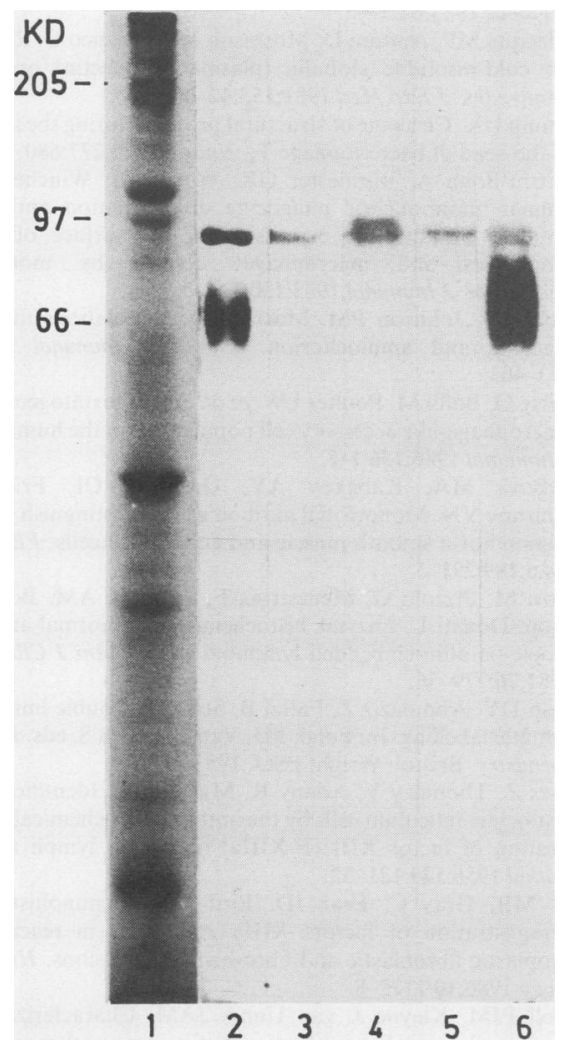

Fig 7 SDS-PAGE pattern of placental macrophage extract (track 1; $120 \mu \mathrm{g}$ protein) and factor XIII (track 2; $5 \mu \mathrm{g}$ ) stained by Coomassie blue. Identical segments of gel electroblotted to nitrocellulose paper were developed for factor XIII subunits a (tracks 3, 4) and b (tracks 5, 6). Electrophoretic mobility of molecular density marker proteins are indicated (left). Note that single band of placental cell extract that reacts with antiserum against factor XIII subunit a has identical mobility with a subunit of purified factor XIII.

Johnson, ${ }^{23}$ might be based on the development of fetal cells in the absence of extrinsic antigens when immune activation of macrophages does not occur. According to Janossy et al, ${ }^{24}$ RFD7-positive macrophages express HLA-DR when induced by immune response mediators. This hypothesis is also supported by the report $^{32}$ that $\alpha$-fetoprotein inhibits macrophage expression of Ia antigens.

The negativity of Kupffer cells for factor XIII subunit $a$ is a surprising finding, but the monocytic origin of these macrophages is strongly debated and they are regarded by some authors as an independent cell population derived from interstitial cells. ${ }^{334}$ Alternatively, they might have lost their factor XIII content during a special differentiation process.

Using the commercially available antibody of the same source directed against the $b$ subunit, Fear et $a l,{ }^{12}$ like us, obtained a positive immunomorphological reaction for this antigen in connective tissue cells containing subunit $a$. In the former study, however, the specificity of the antibody was not checked, thus a cross reaction with the $a$ subunit can not be excluded. In our study this problem was dealt with by immunoblotting. The two subunits of factor XIII have different mobility in $10 \%$ SDS-PAGE, and after electroblotting the separated protein bands a clear distinction can be made between $a$ and $b$ subunits. In this system the antiserum against the $b$ subunit showed a clearly detectable cross reaction with subunit $a$. It was also clearly shown that placental macrophages which gave a positive immunomorphological reaction were indeed devoid of subunit $b$. Though trypsinisation used for the separation of placental macrophages may destroy surface antigens, the staining obtained by the antiserum against subunit $b$ showed intracellular localisation - that is, the antigen detected by it is in all probability inaccessible to the proteolytic enzyme. Furthermore, even if the $b$ subunit had been present but had been degraded by trypsin, lower molecular weight split products should have been picked up in the blotting system by the polyclonal antibody.

In conclusion, our findings strongly suggest that connective tissue macrophages contain subunit $a$, but not subunit $b$ of factor XIII; the positive immunomorphological reaction for the latter was due to the cross reaction of antiserum used. This finding agrees with Bohn's earlier results, which showed the absence of subunit $b$ in placental extract. ${ }^{35}$ As far as the role of factor XIII in macrophages in the formation of connective tissue matrix and in wound healing is concerned, only hypotheses can be postulated.

In their study of the role of the monocyte/macrophage cell line in wound repair, Leibovich and Ross ${ }^{36}$ found that macrophage depletion during wound healing resulted in considerable delay in fibroblast proliferation. They hypothesised that macrophages promote fibroblast proliferation through the production of a factor (or factors). Factor XIII in tissue macrophages might be one such factor. Further investigations on this subject may contribute to a better understanding of connective tissue homeostasis and pathological changes in scar formation.

We thank Dr N Kapusz of the department of forensic medicine for providing us with tissue and $\mathrm{Dr} Z \mathrm{Z}$ Nemes of the department of pathology for taking photographs on enzyme cytochemical preparations. We also thank Mrs A Bana for expert technical help and Mrs M Kozma for typing the manuscript. The dilution of culture supernatant was kindly provided by Professor Janossy.

This study was supported by the Hungarian Minis- 
try of Health, the Hungarian Academy of Sciences (contract No 1-3-86-298), and the National Science Foundation (contract No 1890).

\section{References}

I Muszbek L, Laki K. Interaction of thrombin with proteins other than fibrinogen (thrombin susceptible bonds). Activation of FXIII. In: Machovich R, ed. The Thrombin. Vol 1. Boca Raton: CRC Press, 1984:321-42.

2 Buluk K. An unknown function of blood platelets. Polski Tygod Lekar 1955;10:191.

3 Lüscher EF. Ein fibrinstabilisierender Faktor aus Thrombocyten. Schweiz Med Wochenschr 1957;87:1220-1.

4 Muszbek L, Ádány R. Szegedi G, Polgár J, Kávai M. Factor XIII of blood coagulation in human monocytes. Thromb Res 1985:37:401-10.

5 Henriksson P, Becker S, Lynch G. McDonagh J. Identification of intracellular factor XIII in human monocytes and macrophages. J Clin Invest 1985;76:528-34.

6 Beck E. Duckert F. Ernst M. The influence of fibrin stabilizing factor on the growth of fibroblasts in vitro and wound healing. Thromb Haemostas 1961;6:485-91.

7 Duckert F. Documentation of the plasma factor XIII deficiency in man. Ann NY Acad Sci 1972;202:190-9.

8 Bruhn HD, Pohl J. Growth regulation of fibroblasts by thrombin factor XIII and fibronectin. Klin Wochenschr 1981;59:145-6.

9 Keski-Oja J, Mosher DF, Vaheri A. Cross-linking of major fibroblast surface-associated glyco-protein (fibronectin) catalyzed by blood coagulation factor XIII. Cell 1976;9:29-35.

10 Mosher DF. Labeling of a major fibroblast surface protein (fibronectin) catalyzed by blood coagulation factor XIII Biochim Biophys Acta 1977;491:205-10.

11 Mosher DF, Schad PE, Vann JM. Cross-linking of collagen and fibronectin by factor XIIIa. $J$ Biol Chem 1980;255:1181-8.

12 Fear JD, Jackson P, Gray C, Miloszewski KJA, Losowsky MS Localisation of factor XIII in human tissues using an immunoperoxidase technique. J Clin Pathol 1984;37:560-3.

13 Ádány R, Belkin A. Vasilevskaya T, Muszbek L. Identification of blood coagulation factor XIII in human macrophages. Eur $J$ Cell Biol 1985;38:171-3.

14 Ádány R, Nemes Z, Muszbek L. Characterization of factor XIII containing macrophages in lymph nodes with Hodgkin's disease. Br J Cancer 1987;55:421-6.

15 Ádány R, Kappelmayer J, Muszbek L. Expression of factor XIII subunit a in different types of human macrophages. In: Mauri $C$ Rizzo SC, Rivevuti G, eds. Oxford: Pergamon Press, 1987.

16 Lasser A. The mononuclear phagocytic system: a review. Hum Pathol 1983;14:108-26.

17 Brown MS, Dana SE, Goldstein JL. Regulation of 3-hydroxy-3methylglutaryl coenzym $A$ reductase activity in cultured human fibroblasts. J Biol Chem 1979;249:789-96.

18 Butterworth BH, Loke YW. Immunocytochemical identification of cytotrophoblast from other mononuclear cell populations isolated from first trimester human chorionic villi. J Cell Sci 1985;76:189-97.

19 Freundlich B, Avdalovic N. Use of gelatin/plasma coated flasks for isolating human peripheral blood monocytes. J Immunol
Methods 1983:62:31-7.

20 Bevilacqua MP, Amrani D, Mosesson MW, Bianco C. Receptor for cold-insoluble globulin (plasma fibronectin) on human monocytes. J Exp Med 1981;153:42-60.

21 Laemmli UK. Cleavage of structural proteins during the assembly of the head of bacteriophage $T_{4}$. Nature 1970;277:680.

22 Dimitriu-Bona A, Burmester GR, Waters SJ, Winchester RJ. Human mononuclear phagocyte differentiation antigens. I. Patterns of antigenic expression of the surface of human monocytes and macrophages defined by monoclonal antibodies. J Immunol 1983;130:145-52.

23 Bulmer JN, Johnson PM. Macrophage populations in human placenta and amniochorion. Clin Exp Immunol 1984;57: 393-403.

24 Janossy G, Bofill M, Poulter LW, et al. Separate ontogeny of two macrophage-like accessory cell populations in the human fetus. J Immunol 1986:136:1-8.

25 Glukhova MA, Kabakov AY, Ornatsky OI, Frid MG, Smirnov VN. Monoclonal antibodies that distinguish between human aorta smooth muscle and endothelial cells. FEBS Lett 1985:189:291-5.

26 Chilosi M, Pizzolo G, Menestrina F, Iannucci AM, Bonetti F, Fiore-Donati L. Enzyme histochemistry on normal and pathologic paraffin-embedded lymphoid tissues. Am J Clin Pathol 1981;76:729-36.

27 Mason DY, Abdulaziz Z, Falini B, Stein H. Double immunoenzymatic labelling. In: Polak MJ, Van Noorden S, eds. Immunochemistry. Bristol: Wright PSG, 1983:113-28.

28 Nemes Z, Thomázy V, Adány R, Muszbek L. Identification of histiocytic reticulum cells by the immunohistochemical demonstration of factor XIII (F-XIIIa) in human lymph nodes. $J$ Pathol 1986;149:121-32.

29 Reid MB, Gray C, Fear JD, Bird CC. Immunohistological demonstration of factors XIIIa and XIIIs in reactive and neoplastic fibroblastic and fibro-histiocytic lesions. Histopathology 1986;10:1172-8.

30 Roholl PJM, Kleyne J, van Unnik JAM. Characterization of tumor cells in malignant fibrous histiocytoma other soft tissue tumors in comparison with malignant histiocytes: II. Immunoperoxidase study on cryostat sections. Am J Pathol 1985;121:269-74.

31 Strauchen JA, Dimitriu-Bona A. Malignant fibrous histiocytoma. Expression of moncyte/macrophage differentiation antigens detected with monoclonal antibodies. Am J Pathol 1986; 124:303-9.

32 Lu CY, Changelian PS, Unanue ER. $\alpha$-Fetoprotein inhibits macrophage expression of Ia antigens. $J$ Immunol 1984;132:1722-7.

33 Wisse E. Kupffer cell reactions in rat liver under various conditions as observed in the electron microscope. J Ultrastruct Res 1974; 46:499-520.

34 Widmann JJ, Fahimi HD. Proliferation of mononuclear phagocytes (Kupffer cells) and endothelial cells in regenerating rat liver. Am J Pathol 1975;80:349-66.

35 Bohn $\mathrm{H}$. The human fibrin-stabilizing factors $\mathrm{Mol} \mathrm{Cell} \mathrm{Biochem}$ 1978;20:67-75.

36 Leibovich SJ, Ross $R$. The role of the macrophage in wound repair. Am J Pathol 1975:78:71-100.

Requests for reprints to: Dr $\mathbf{R}$ Ádány, Department of Clinical Chemistry, University School of Medicine, H-4032 Debrecen, PO Box 40, Hungary. 